\title{
CLINICAL RESEARCH ARTICLE Fetal exposure to mercury and lead from intrauterine blood transfusions
}

\author{
Alison J. Falck ${ }^{1}$, Sripriya Sundararajan ${ }^{1}$, Faeq Al-Mudares ${ }^{2}$, Stephen A. Contag ${ }^{3}$ and Cynthia F. Bearer ${ }^{1}$
}

BACKGROUND: Mercury $(\mathrm{Hg})$ and lead $(\mathrm{Pb})$ exposure during childhood is associated with irreversible neurodevelopmental effects. Fetal exposure to $\mathrm{Hg}$ and $\mathrm{Pb}$ from intrauterine blood transfusion (IUBT) has not been reported.

METHODS: Fetal exposure was estimated based on transfusion volume and metal concentration in donor packed red blood cell (PRBCs). As biomarkers to quantify prenatal exposure are unknown, $\mathrm{Hg}$ and $\mathrm{Pb}$ in donor PRBCs were compared to estimated intravenous (IV) RfDs based on gastrointestinal absorption.

RESULTS: Three pregnant women received 8 single-donor IUBTs with volumes ranging from 19 to $120 \mathrm{~mL} / \mathrm{kg}$. $\mathrm{Hg}$ and $\mathrm{Pb}$ were present in all donor PRBC units. In all, 1/8 IUBT resulted in $\mathrm{Hg}$ dose five times higher than the estimated IV RfD. Median Pb dose in one fetus who received 5 single-donor IUBTs between $20-32$ weeks gestation was $3.4 \mu \mathrm{g} / \mathrm{kg}$ (range $0.5-7.9 \mu \mathrm{g} / \mathrm{kg}$ ). One donor unit contained $12.9 \mu \mathrm{g} / \mathrm{dL}$ of $\mathrm{Pb}$, resulting in a fetal dose of $7.9 \mu \mathrm{g} / \mathrm{kg}$, 40 times higher than the estimated IV RfD at 20 weeks gestation.

CONCLUSION: This is the first study documenting inadvertent exposure to $\mathrm{Hg}$ and $\mathrm{Pb}$ from IUBT and quantifying the magnitude of exposure. Screening of donor blood is warranted to prevent toxic effects from $\mathrm{Hg}$ and $\mathrm{Pb}$ to the developing fetus.

Pediatric Research (2019) 86:510-514; https://doi.org/10.1038/s41390-019-0463-z

\section{INTRODUCTION}

Exposure to the heavy metals mercury $(\mathrm{Hg})$ and lead $(\mathrm{Pb})$ has adverse effects to the developing brain, in addition to detrimental effects to the reproductive, renal, and cardiovascular health. ${ }^{1} \mathrm{~Pb}$ exposure can affect nearly every system in the body with irreversible effects. ${ }^{1}$ While no safe blood $\mathrm{Pb}$ level in children has been identified, even low levels of $\mathrm{Pb}$ in blood have been shown to affect learning, memory, attention, cognitive function, and academic achievement. ${ }^{2,3}$ The Center for Disease Control (CDC) recommends public health actions be initiated when blood $\mathrm{Pb}$ levels exceed $5 \mu \mathrm{g} / \mathrm{dL}^{4}{ }^{4}$ The current focus is on primary prevention and to prevent $\mathrm{Pb}$ exposure before it occurs. Thereafter protection from exposure to heavy metals starting from the period of conception is important to lifelong good health.

Both $\mathrm{Hg}$ and $\mathrm{Pb}$ are known neurotoxins that impact fetal brain development, resulting in adverse neurodevelopmental outcomes in children exposed prenatally. ${ }^{5,6} \mathrm{Hg}$ and $\mathrm{Pb}$ are both lipid-soluble heavy metals that bind hemoglobin, concentrate in red blood cells, and readily cross the blood-brain barrier. ${ }^{2,7} \mathrm{Hg}$ and $\mathrm{Pb}$ have been found consistently in blood samples collected annually by the U.S. Center for Disease Control (CDC) National Health and Nutrition Examination Survey. ${ }^{5,8}$ Blood products including whole blood, donor packed red blood cells (PRBCs), platelets, and plasma, routinely used for neonatal transfusions, are known sources of $\mathrm{Pb}$ and $\mathrm{Hg}$ exposure to infants. ${ }^{9,10}$ Our previous studies have shown that very premature infants at $<30$ weeks of gestation are exposed to the heavy metal Pb through RBC transfusions and that $\mathrm{Pb}$ exposure from $\mathrm{RBC}$ transfusion may exceed established safety limits. ${ }^{11,12}$

Prenatal exposure to $\mathrm{Hg}$ and $\mathrm{Pb}$ from intrauterine blood transfusion (IUBT) has never before been studied. Currently, donor PRBCs that are used for IUBT are not prescreened for heavy metals. Thus IUBT, a lifesaving treatment for fetal anemia, could potentially expose the fetus to these metals during critical periods of fetal brain development. Ours is the first study to investigate and estimate the burden of fetal heavy metal exposure from IUBT.

\section{METHODS}

Following approval of the study protocol by The University of Maryland School of Medicine institutional review board, this study was conducted between October 2014 and May 2015 at the University of Maryland Medical Center.

\section{IUBT practice}

Top-up intravascular fetal transfusion was performed for all of the IUBTs. The volume of blood for each IUBT was determined based on the measured fetal hemoglobin/hematocrit, the target hematocrit of the fetus, the hematocrit of the transfused RBCs, and estimated fetal weight (EFW). After identifying fetuses at risk for moderate-to-severe anemia by both hematocrit and middle cerebral artery peak systolic velocity, consent was obtained for the IUBT procedure. In the operating room and under intravenous (IV) sedation, the position of the fetus, placenta, and the cord insertion site on the placenta were identified by ultrasound. A 21-gauge

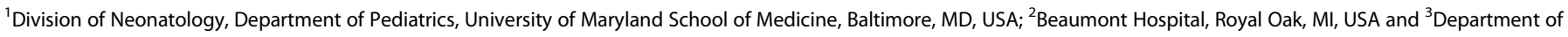
Obstetrics, Gynecology and Women's Health, University of Minnesota, Minneapolis, MN, USA

Correspondence: Alison J. Falck (afalck@som.umaryland.edu)

These authors contributed equally: Alison J. Falck, Sripriya Sundararajan

Received: 15 September 2018 Revised: 4 June 2019 Accepted: 12 June 2019

Published online: 19 June 2019 
needle was introduced into the fetal umbilical vein at the placental insertion site. For posterior placentas or where the fetus is interposed between abdominal insertion site and the cord insertion site of the placenta, the fetus was first given a single dose of Vecuronium $0.1 \mathrm{mg} / \mathrm{kg}$ EFW. Compatible cytomegalovirusnegative, irradiated, leukoreduced, and washed PRBCs were then transfused through the needle into the fetal umbilical vein. Fetal heart rate was intermittently monitored by ultrasound throughout the procedure. When infusion was completed, another fetal blood sample was obtained to check the post-transfusion hematocrit. A medical record review was performed to determine gestational age $(G A)$ in weeks at the time of IUBT, transfusion volume $(\mathrm{ml})$, and EFW (g).

Determination of metal content in PRBC unit

After a request for IUBT with PRBCs to correct fetal anemia secondary to immune hemolytic anemia, $1 \mathrm{~mL}$ of donor PRBCs was collected as a segment in the blood bank from the designated donor PRBC unit for IUBT use. Samples from 8 single donors were collected and stored at $-20^{\circ} \mathrm{C}$. Metal content in donor PRBC segments was measured as total concentration of $\mathrm{Hg}(\mu \mathrm{g} / \mathrm{L})$ and $\mathrm{Pb}(\mu \mathrm{g} / \mathrm{dL})$ using inductively coupled plasma mass spectroscopy (ICP-MS, Elan DRC-II, Perkin-Elmer, Waltham, MA). The lower limit of detection for both metals was $0.1 \mu \mathrm{g} / \mathrm{L}$. Accuracy and precision of metal analysis was tested using the external quality control program of the CDC (Wisconsin State Laboratory of Hygiene).

\section{Reference doses (RfDs) for $\mathrm{Hg}$ and $\mathrm{Pb}$}

Biomarkers to quantify prenatal exposure to $\mathrm{Hg}$ and $\mathrm{Pb}$ have not been established. Moreover, no exposure to $\mathrm{Pb}$ can be considered safe and no safe intake level for $\mathrm{Pb}$ currently exists. $\mathrm{RfD}$, a measure to define thresholds of exposure, is defined as an estimate (with uncertainty spanning perhaps an order of magnitude) of a daily exposure to humans (including sensitive subgroups) that is likely to be without an appreciable risk of deleterious effects during one's lifetime. ${ }^{13}$ In order to quantify fetal $\mathrm{Hg}$ and $\mathrm{Pb}$ exposure from PRBC transfusions based on donor PRBC concentration, each IUBT was considered as an IV dose of $\mathrm{Hg}$ and $\mathrm{Pb}$. As IV RfDs have not been characterized, we used estimated IV RfDs that were calculated from oral RfDs based on gastrointestinal (GI) absorption as previously published by Elabiad et al. ${ }^{14}$ The U.S. Environmental Protection Agency has established an oral RfD of $0.1 \mu \mathrm{g} / \mathrm{kg} / \mathrm{day}$ for $\mathrm{Hg}{ }^{15}$ The higher oral $\mathrm{Pb}$ intake of $1.9 \mu \mathrm{g} / \mathrm{kg} /$ day, defined by the Joint Food and Agriculture Organization/World Health Organization Expert Committee on Food Additives to be of concern due to a population decrease of 3 IQ points, ${ }^{16}$ was used as the oral RfD to compare $\mathrm{Pb}$ doses given with each blood transfusion. ${ }^{14}$ With $95 \%$ of oral $\mathrm{Hg}$ intake and $10 \%$ of oral $\mathrm{Pb}$ intake being absorbed, ${ }^{15,17}$ the corresponding estimated IV RfDs would be $0.095 \mu \mathrm{g} / \mathrm{kg} / \mathrm{day}$ for $\mathrm{Hg}$ and $0.19 \mu \mathrm{g} / \mathrm{kg} /$ day for $\mathrm{Pb}^{10}$ in children, respectively, as shown in Fig. 1.

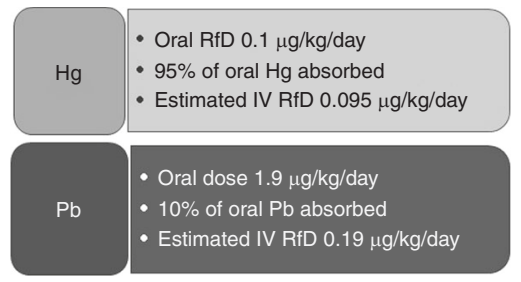

Fig. 1 Calculation of estimated intravenous (IV) reference doses (RfD) for $\mathrm{Hg}$ and $\mathrm{Pb}$ from oral $\mathrm{RfD}$ based on gastrointestinal absorption of heavy metals
Estimating $\mathrm{Hg}$ and $\mathrm{Pb}$ dose per IUBT

We initially determined the fetal metal dose in donor RBC based on the measured concentration of $\mathrm{Hg}(\mu \mathrm{g} / \mathrm{L})$ and $\mathrm{Pb}(\mu \mathrm{g} / \mathrm{dL})$ content in donor PRBCs by ICP-MS. Metal dose per transfusion was subsequently calculated with the following equation: volume of blood transfused $(\mathrm{ml}) \times \mathrm{PRBC}$ metal level $(\mu \mathrm{g} / \mathrm{L}) /$ estimated fetal weight $(\mathrm{kg})=$ estimated IV metal dose $(\mu \mathrm{g} / \mathrm{kg} /$ day $)$. Finally, we quantified the burden of $\mathrm{Hg}$ and $\mathrm{Pb}$ exposure from IUBT by comparing the result of the calculated fetal IV metal dose per transfusion with the estimated IV RfD for $\mathrm{Hg}$ and $\mathrm{Pb} .^{10,14}$

\section{RESULTS}

Three pregnant women received a total of 8 single-donor IUBTs ( $n$ $=5,2$, and 1 IUBT per fetus, respectively) for treatment of fetal anemia secondary to immune hemolytic anemia. At the time of IUBT, fetal GA ranged from 20 to 34 weeks and EFW was 396-2568 $\mathrm{g}$ (Table 1). The etiology of hemolytic anemia in fetus 1 was anti-Kell alloimmunization, while fetuses 2 and 3 required IUBT for treatment of $\mathrm{Rh}$ isoimmunization. IUBT volume ranged from 19 to $120 \mathrm{~mL} / \mathrm{kg}$, based on EFW (Table 1). $\mathrm{Hg}$ and $\mathrm{Pb}$ were present in all 8 donor PRBC units. Median donor $\mathrm{Hg}$ concentration was $1.8 \mu \mathrm{g} / \mathrm{L}$ (range $0.7-3.7$ ), while median donor $\mathrm{Pb}$ concentration was $3.7 \mu \mathrm{g} / \mathrm{dL}$ (range 0.9-12.9) (Table 1).

Exposure to IUBT resulted in a median estimated fetal IV dose of $0.07 \mu \mathrm{g} / \mathrm{kg}$ (range 0.04-0.44; Fig. 2a) for $\mathrm{Hg}$ and $1.1 \mu \mathrm{g} / \mathrm{kg}$ (range 0.5-7.9; Fig. 2b) for Pb. In these IUBTs, $1 / 8$ and $8 / 8$ contained doses of $\mathrm{Hg}$ and $\mathrm{Pb}$ that were greater than the estimated IV RfDs (Fig. 2a, b).

Magnitude of exposure in fetus 1

Fetus 1 received a total of 5 IUBTs between 20 and 32 weeks GA from 5 single donors. In this fetus, the median $\mathrm{Pb}$ dose among the 5 IUBTs was $3.4 \mu \mathrm{g} / \mathrm{kg}$ (range $0.5-7.9 \mu \mathrm{g} / \mathrm{kg}$ ). At 22 weeks GA and an EFW of $500 \mathrm{~g}$, a single IUBT of $120 \mathrm{~mL} / \mathrm{kg}$ resulted in concurrent fetal doses of $\mathrm{Hg}$ of $0.45 \mu \mathrm{g} / \mathrm{Kg}$ (5 times the IV RfD) and $\mathrm{Pb}$ of 4.4 $\mu \mathrm{g} / \mathrm{kg}$ (23 times the IV RfD) (Table 1). Of added concern, this fetus received an additional single-donor IUBT at 28 weeks GA $(61 \mathrm{~mL} /$ $\mathrm{kg}$ ) with almost $13 \mu \mathrm{g} / \mathrm{dL}$ of $\mathrm{Pb}$ (Table 1). This represents an estimated IV Pb dose of $8 \mu \mathrm{g} / \mathrm{kg},>40$ times the estimated IV RfD (Table 1).

\section{DISCUSSION}

This is the first study to quantify in utero exposure to $\mathrm{Hg}$ and $\mathrm{Pb}$ as early as 20 weeks gestation from an IUBT procedure. In this study, all eight single-donor PRBC units utilized for IUBT contained $\mathrm{Hg}$ and $\mathrm{Pb}$. Multiple IUBT procedures resulted in delivering substantial higher concentrations of $\mathrm{Hg}$ and $\mathrm{Pb}$ that is much greater than the estimated IV RfD, with one instance of $\mathrm{Pb}$ exposure $>40$ times the estimated IV RfD. This magnitude of exposure is much higher and much more significant than previously shown in the literature that evaluated $\mathrm{Hg}$ and $\mathrm{Pb}$ exposure from PRBC transfusions in premature infants. ${ }^{11,18}$

The fetus is highly susceptible to neurotoxins during periods of rapid neuronal cell division and proliferation. While organogenesis is complete in most organ systems by 8 weeks GA, central nervous system development is not complete until well into infancy and beyond. ${ }^{19}$ Fetal central nervous system remains vulnerable to teratogens across fetal development and following birth. Exposure to neurotoxins such as $\mathrm{Hg}$ and $\mathrm{Pb}$ may impact neuronal differentiation, proliferation, migration, and myelination leading to permanent neuronal loss and impaired neurodevelopment. ${ }^{20}$

The primary source of methyl $\mathrm{Hg}$ (organic $\mathrm{Hg}$ ) is dietary, through ingestion of fish. ${ }^{21}$ Fetal exposure to methyl $\mathrm{Hg}$ has been linked to neurocognitive and neurosensory impairment and neurobehavioral disorders such as attention-deficit/hyperactivity disorder (ADHD). ${ }^{5,20} \mathrm{Hg}$ levels tend to be higher in cord blood 
than in maternal blood. ${ }^{22} \mathrm{Hg}$, well known to cross the placenta, is effluxed through glutathione conjugation to be transported primarily toward the fetal side. ${ }^{23}$ The fetal brain is more susceptible to $\mathrm{Hg}$-induced injury than the adult brain, as $\mathrm{Hg}$ inhibits the division and migration of neuronal cells that result in disruption of the developing brain cyto-architecture. ${ }^{24}$ Prenatal methyl $\mathrm{Hg}$ exposure as determined from $\mathrm{Hg}$ analyses of cord blood, cord tissue, and maternal hair has been significantly associated with deficits in motor, attention, and verbal tests at 14 years of age. ${ }^{25}$

$\mathrm{Pb}$ is a potent neurotoxic heavy metal; the central and peripheral nervous systems are highly vulnerable to the toxic effects of $\mathrm{Pb}^{20}$ Fetal central nervous system exposure to $\mathrm{Pb}$ is associated with neurocognitive impairment, altered executive functioning, developmental disorders of scholastic skills, and other social and neurobehavioral disorders, including ADHD. ${ }^{5,20} \mathrm{~Pb}$ has been shown to have detrimental effects on brain development through alteration of neurite outgrowth ${ }^{26}$; substitution for calcium in critical enzymatic processes, including metal transport, energy metabolism, apoptosis, protein maturation, and genetic regulation ${ }^{27,28}$; and inhibiting neurite initiation through alteration of enzyme protein kinase C (calcium-dependent enzyme) resulting in blockade of voltage-dependent calcium channels and disruption of neuronal activity. ${ }^{2}$ Deleterious effects from infantile $\mathrm{Pb}$ exposure that result in severe motor and cognitive impairments are far greater in children than in adults. ${ }^{29,30}$ Increasing levels of blood $\mathrm{Pb}$ were found inversely associated with cognitive performance and neuropsychological development through the first 7 years of life. ${ }^{31}$

Blood $\mathrm{Pb}$ is a representative of soft tissue lead and is the primary biomarker most commonly used for the assessment of $\mathrm{Pb}$ exposure, both for screening and diagnostic purposes and for biomonitoring body burden. ${ }^{2} \mathrm{~Pb}$ moves freely from erythrocyte into the plasma and to the various body compartments including umbilical cord blood; brain; bone; and soft tissues such as hair, nail, saliva, tooth, and urine. The half-life of $\mathrm{Pb}$ varies from about a month in blood, about 2 years in the brain, to about 25-30 years in the bone. ${ }^{27}$ As plasma fraction of $\mathrm{Pb}$ is rapidly exchangeable in the blood, toxic effects of $\mathrm{Pb}$ are assumed to be associated with plasma $\mathrm{Pb}$. But accurate determination of plasma $\mathrm{Pb}$ is challenging due to shift of $\mathrm{Pb}$ into the plasma from erythrocyte hemolysis. ${ }^{32}$ The blood $\mathrm{Pb}$ concentration that actually relates to brain extracellular concentration is not known. Maternal blood $\mathrm{Pb}$ concentration is highly correlated with umbilical cord $\mathrm{Pb}$, suggesting trans-placental transfer of $\mathrm{Pb}$ to the fetus. ${ }^{33}$ In fact, $\mathrm{Pb}$ readily crosses the placenta both by passive diffusion and actively transported by divalent metal ion transporters. ${ }^{34-36} \mathrm{~Pb}$ has been measured in the fetal brain as early as the end of the first trimester (13 weeks). ${ }^{34,37}$ Following exposure, potentially via IUBT, these lipid-soluble metals cross the immature blood-brain barrier and can bioaccumulate in the fetal brain. ${ }^{38}$

A major excretory route for heavy metal is through the Gl tract. ${ }^{39,40}$ In contrast to the newborn, the fetus has minimal Gl excretory abilities, which potentially could contribute to further bioaccumulation of $\mathrm{Hg}$ and $\mathrm{Pb}$ in the fetal compartment.

In conclusion, while IUBT is a life-saving therapy for fetal anemia, this is the first study to report fetal exposure to $\mathrm{Hg}$ and $\mathrm{Pb}$ of variable amounts exceeding estimated IV RfDs that could potentially have extremely harmful consequences. This study further confirms and only complements what is already known for decades regarding blood products as a known source of $\mathrm{Hg}$ and $\mathrm{Pb}$ exposure in infants. Biomarkers in blood to quantify in utero exposure to $\mathrm{Hg}$ and $\mathrm{Pb}$ have not been established, and toxic threshold levels to the developing fetal brain are unknown. Until biomarkers of $\mathrm{Hg}$ and $\mathrm{Pb}$ in blood are identified, screening of donor blood for these known neurotoxins is imperative and must be a priority for this highly specialized and vulnerable population. 

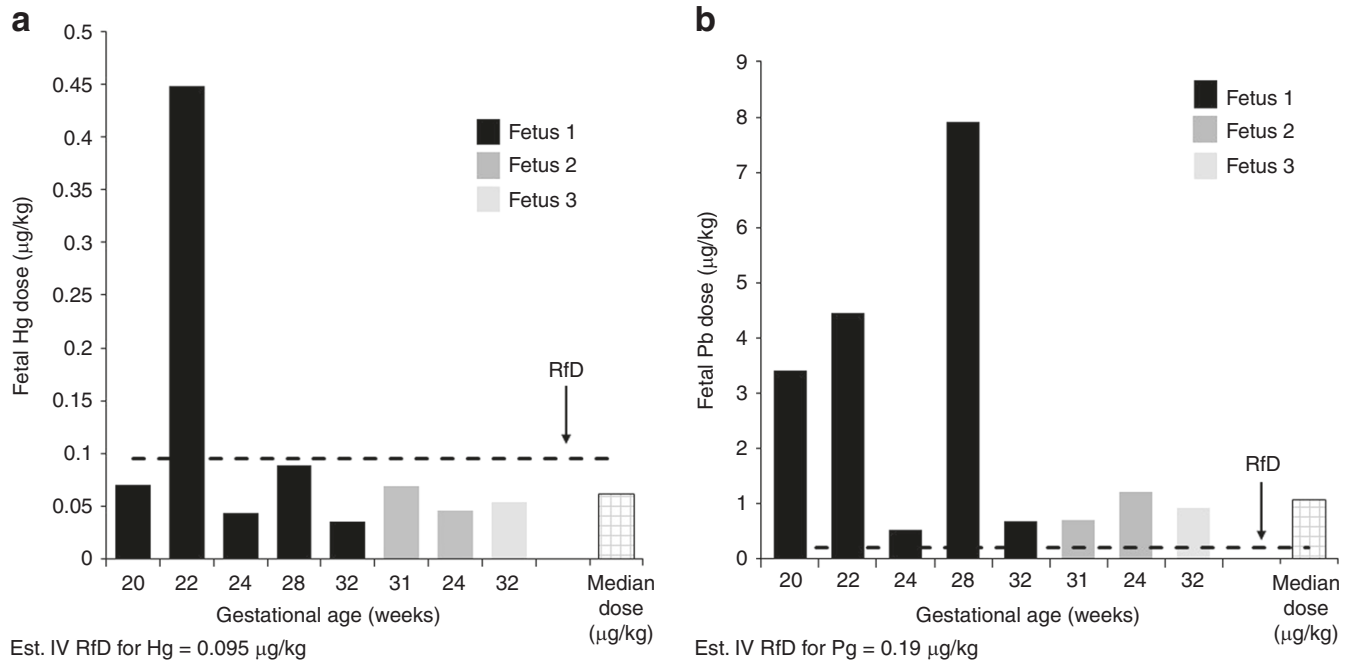

Fig. 2 Fetal doses of $\mathrm{Hg}(\mathbf{a})$ and $\mathrm{Pb}(\mathbf{b})$ as compared to estimated intravenous reference dosesfrom eight single-donor intrauterine blood transfusions of packed red blood cells

\section{ACKNOWLEDGEMENTS}

We gratefully acknowledge the contribution of the late Dr. Prince A.K. Kassim for assistance with the blood sample analysis for heavy metals.

\section{AUTHOR CONTRIBUTIONS}

Substantial contributions to conception and design, acquisition of data, or analysis and interpretation of data-all authors. Drafting the article or revising it critically for important intellectual content-AJF and SS. Final approval of the version to be published-all authors.

\section{ADDITIONAL INFORMATION}

Competing interests: The authors declare no competing interests.

Publisher's note: Springer Nature remains neutral with regard to jurisdictional claims in published maps and institutional affiliations.

\section{REFERENCES}

1. NTP monograph on health effects of low-level lead. NTP Monogr. xiii, xv-148 (2012).

2. Sanders, T., Liu, Y., Buchner, V. \& Tchounwou, P. B. Neurotoxic effects and biomarkers of lead exposure: a review. Rev. Environ. Health 24, 15-45 (2009).

3. Khanna, M. M. Boys, not girls, are negatively affected on cognitive tasks by lead exposure: a pilot study. J. Environ. Health 77, 72-77 (2015).

4. Centers for Disease Control and Prevention. Low Level Lead Exposure Harms Children: A Renewed Call for Primary Prevention. Report of Advisory Committee on Childhood Lead Poisoning Prevention (CDC, Atlanta, GA, 2012).

5. Bellinger, D. C. Prenatal exposures to environmental chemicals and children's neurodevelopment: an update. Saf. Health Work 4, 1-11 (2013).

6. Hong, Y.-S., Kim, Y.-M. \& Lee, K.-E. Methylmercury exposure and health effects. J. Prev. Med. Public Health 45, 353 (2012).

7. Zheng, W., Aschner, M. \& Ghersi-Egea, J. F. Brain barrier systems: a new frontier in metal neurotoxicological research. Toxicol. Appl. Pharm. 192, 1-11 (2003).

8. Mortensen, M. E., Caudill, S. P., Caldwell, K. L., Ward, C. D. \& Jones, R. L. Total and methyl mercury in whole blood measured for the first time in the US population: NHANES 2011-2012. Environ. Res. 134, 257-264 (2014).

9. Aly, S. M., Omran, A., Abdalla, M. O., Gaulier, J. M. \& El-Metwally, D. Lead: a hidden "untested" risk in neonatal blood transfusion. Pediatr. Res. 85, 50-54 (2019).

10. Elabiad, M. T. \& Christensen, M. Changes in premature infant mercury and lead blood levels after blood transfusions. Am. J. Perinatol. 31, 863-868 (2014).

11. Bearer, C. F., Linsalata, N., Yomtovian, R., Walsh, M. \& Singer, L. Blood transfusions: a hidden source of lead exposure. Lancet 362, 332 (2003).

12. Bearer, C. F., O'Riordan, M. A. \& Powers, R. Lead exposure from blood transfusion to premature infants. J. Pediatr. 137, 549-554 (2000).
13. Barnes, D. G. et al. Reference dose (RfD): description and use in health risk assessments. Regul. Toxicol. Pharmacol. 8, 471-486 (1988).

14. Elabiad, M. T. \& Hook, R. E. Lead content of blood transfusions for extremely lowbirth-weight infants. Am. J. Perinatol. 30, 765-770 (2013).

15. Rice, G., Swartout, J., Mahaffey, K. \& Schoeny, R. Derivation of US EPA's oral Reference Dose (RfD) for methylmercury. Drug Chem. Toxicol. 23, 41-54 (2000).

16. Joint FAO. Joint FAO/WHO Expert Committee on Food Additives Seventy-third Meeting (World Health Organization, Geneva, 2010.

17. Elabiad, M. T. \& Hook, R. E. Mercury content of blood transfusions for infants with extremely low birth weight. Pediatrics 128, 331-334 (2011).

18. Zubairi, H., Visintainer, P., Fleming, J., Richardson, M. \& Singh, R. Lead exposure in preterm infants receiving red blood cell transfusions. Pediatr. Res 77, 814-818 (2015).

19. Budday, S., Steinmann, P. \& Kuhl, E. Physical biology of human brain development. Front. Cell. Neurosci. 9, 257 (2015)

20. Falck, A. J. et al. Developmental exposure to environmental toxicants. Pediatr. Clin. North Am. 62, 1173-1197 (2015).

21. Ramon, R. et al. Prenatal mercury exposure in a multicenter cohort study in Spain Environ. Int. 37, 597-604 (2011)

22. Sakamoto, M., Chan, H. M., Domingo, J. L., Koriyama, C. \& Murata, K. Placental transfer and levels of mercury, selenium, vitamin $E$, and docosahexaenoic acid in maternal and umbilical cord blood. Environ. Int 111, 309-315 (2018).

23. Straka, E. et al. Mercury toxicokinetics of the healthy human term placenta involve amino acid transporters and $A B C$ transporters. Toxicology 340, 34-42 (2016).

24. Clarkson, T. W., Magos, L. \& Myers, G. J. The toxicology of mercury-current exposures and clinical manifestations. N. Engl. J. Med. 349, 1731-1737 (2003).

25. Debes, F., Budtz-Jorgensen, E., Weihe, P., White, R. F. \& Grandjean, P. Impact of prenatal methylmercury exposure on neurobehavioral function at age 14 years. Neurotoxicol. Teratol. 28, 536-547 (2006).

26. Yu, C. L., Zhao, X. M. \& Niu, Y. C. Ferulic acid protects against lead acetate-induced inhibition of neurite outgrowth by upregulating HO-1 in PC12 cells: involvement of ERK1/2-Nrf2 pathway. Mol. Neurobiol. 53, 6489-6500 (2016).

27. Garza, A., Vega, R. \& Soto, E. Cellular mechanisms of lead neurotoxicity. Med. Sci. Monit. 12, RA57-RA65 (2006).

28. Lidsky, T. I. \& Schneider, J. S. Lead neurotoxicity in children: basic mechanisms and clinical correlates. Brain 126, 5-19 (2003).

29. Canfield, R. L. et al. Intellectual impairment in children with blood lead concentrations below 10 microg per deciliter. N. Engl. J. Med. 348, 1517-1526 (2003).

30. Bellinger, D. C., Stiles, K. M. \& Needleman, H. L. Low-level lead exposure, intelligence and academic achievement: a long-term follow-up study. Pediatrics $\mathbf{9 0}$ 855-861 (1992).

31. Baghurst, P. A. et al. Environmental exposure to lead and children's intelligence at the age of seven years. The Port Pirie Cohort Study. N. Engl. J. Med. 327, 1279-1284 (1992).

32. Barbosa, F. Jr., Tanus-Santos, J. E., Gerlach, R. F. \& Parsons, P. J. A critical review of biomarkers used for monitoring human exposure to lead: advantages, limitations, and future needs. Environ. Health Perspect. 113, 1669-1674 (2005). 
Fetal exposure to mercury and lead from intrauterine blood transfusions AJ Falck et al.

514

33. Gardella, C. Lead exposure in pregnancy:: a review of the literature and argument for routine prenatal screening. Obstet. Gynecol. Surv. 56, 231-238 (2001).

34. Goyer, R. A. Transplacental transport of lead. Environ. Health Perspect. 89, 101-105 (1990).

35. Gundacker, C. et al. Genetics of the human placenta: implications for toxicokinetics. Arch. Toxicol. 90, 2563-2581 (2016).

36. Ettinger, A. S. \& Wengrovitz, A. M. Guidelines for the Identification and Management of Lead Exposure in Pregnant and Lactating Women (U.S. Department of Heath and Human Services, Atlanta, 2010).
37. Crinnion, W. J. The CDC Fourth National Report on human exposure to environmental chemicals: what it tells us about our toxic burden and how it assist environmental medicine physicians. Altern. Med. Rev. 15, 101-109 (2010).

38. Bradbury, M. W. \& Deane, R. Permeability of the blood-brain barrier to lead. Neurotoxicology 14, 131-136 (1993).

39. Barltrop, D. \& Killala, N. J. Faecal excretion of lead by children. Lancet 2 , 1017-1019 (1967)

40. Flora, S. J. \& Pachauri, V. Chelation in metal intoxication. Int. J. Environ. Res. Public Health 7, 2745-2788 (2010). 